\title{
Scratch resistance of PEG-impregnated green wood: a method for evaluation of swollen wood properties
}

\author{
Stefania Fortino ${ }^{1} \cdot$ Jarkko Metsäjoki $^{1} \cdot$ Helena Ronkainen ${ }^{1}$. \\ Ingela Bjurhager ${ }^{2}$. Sabine Heinemann ${ }^{3}$. Lauri I. Salminen ${ }^{4}$
}

Received: 2 October 2019 / Published online: 25 April 2020

(c) The Author(s) 2020

\begin{abstract}
This work proposes an experimental approach to study the scratch resistance of green wood under the effect of polyethylene glycol (PEG) impregnation. To this end, smallscale green spruce samples are stabilized against water by using the technique of PEG impregnation to prevent water to seep out of the wood during experimental tests. Scratches are performed in the radial-longitudinal and tangential-longitudinal planes of cubic wood samples by using two different indenter tips under constant and progressive normal loads. Scratch testing has previously been used mainly to characterize the abrasion resistance of coatings. Since PEG simulates the swelling effect of water in wood, this paper shows that the scratch tests on PEG-impregnated green wood can be adopted as a simple technique to understand the scratch resistance in swollen wood and the related mechanisms. The scratch test results, quantified in terms of frictional forces and permanent residual depths, reveal that the scratch resistance of wood samples depends on their PEG concentration and density, as well as on the indenter tip size and material, and on the normal force and direction during scratching. Due to the lack of literature on the scratch tests of wood, the results presented in this paper will serve as a scientific reference for future studies on the scratch resistance of untreated or treated dry wood and other wood-based products.
\end{abstract}

Stefania Fortino

stefania.fortino@vtt.fi

1 VTT Technical Research Centre of Finland Ltd, P.O. Box 1000, 02044 Espoo, Finland

2 Division of Applied Mechanics, Department of Engineering Sciences, Uppsala University, Box 534, 75121 Uppsala, Sweden

3 Institute for Natural Materials Technology, Dresden University of Technology (TU Dresden), Marschnerstr. 39, 01307 Dresden, Germany

4 Andritz Oy, Askonkatu 9 G, 15100 Lahti, Finland 


\section{Introduction}

Wood is a natural and sustainable raw material suited for industrial use as timber, wood products as well as fibres to strengthen polymeric and mineralogical composites (Reid and Zhou 2000; Song et al. 2018). Optimal understanding of the mechanisms involved in wood fibre deformation can improve the knowledge of the material properties of wood. The composite structure of the wood cell walls affects delamination and disintegration relevant to many applications, such as pulp, nano- or microfibril cellulose manufacturing and particleboard defibration. Compared to other structural materials, such as ceramics and metals, wood is not as thoroughly researched in regard to its deformation and disintegration. In addition, wood is more sensitive to moisture than other load-carrying materials, which is why this effect needs to be carefully investigated. Since wood cell deformation and fracture is complex, the research in this area needs to be made stepwise focusing on only a limited number of parameters each time, as discussed in Fortino et al. (2015).

Wood has a well-organized hierarchy, dominated by a cellular and layered structure and is composed of three constituents: lignin, hemicellulose and cellulose (Kollman and Côte 1968). Lignin has no ordered structure and also hemicellulose is amorphous, but cellulose has both crystalline (ordered) and amorphous regions. Cellulose and hemicellulose are hydrophilic, whereas lignin is less hydrophilic than hemicellulose. Cellulose is organized in crystalline and para-crystalline regions. In terms of mechanics, those fractions, along with hemicellulose structures, are responsible for the elastic behaviour in tension. The lignin and hemicellulose of the matrix contribute to the viscoelastic behaviour, but also to the plastic deformations beyond the limit of proportionality. The multitude of different polymeric structures and the presence of both hydrophobic and hydrophilic molecules explain why the mechanical properties of wood are strongly dependent on its water content. As other polymers close to their glass transition temperature, the wood biopolymers are also sensitive to temperature, accentuated by the presence of moisture. Moisture leads to swelling and softening of the cell wall, which will significantly affect the deformation and fracture mechanisms, and ultimately also the strength and structural integrity of the material on larger scales. Therefore, one of the challenges in experiments for the characterization of the mechanical behaviour of wood is testing of wet specimens. Wood chipping and defibration is carried out in the green, i.e. moist, condition. Steam explosion is done saturated in water. Cutting of trees is obviously done in the moist green state. Mechanical testing under moist conditions is therefore of relevance. The relatively small dimensions of the material samples for laboratory testing imply that the moisture content is likely to change during testing, either through diffusion and evaporation into a relatively dry environment or by seepage through mechanical compression. In general, experiments on wood specimens in water are time-consuming, technically challenging and expensive (e.g. De Magistris and Salmén 2006, 2008). According to Bjurhager et al. (2010), the swelling effect of water in wood samples can be simulated by the PEG impregnation. PEG is used as a bulk impregnation agent to maintain the wood in a swollen state mimicking the state of water-saturated wood or wood at certain moisture contents. PEG is a preferred conservation agent in preserving waterlogged archaeological wood, which would otherwise shrink excessively and crack when taken from 
an immersed state and dried in air. The PEG is used as a substitution of water in the cell wall and will remain in the cell wall even under equilibrium conditions in a dry environment and under mechanical loading. In this way, the outward migration of a water substitute during experimental tests could be avoided. At this stage, the tests are carried out on swollen samples with a chosen amount of PEG, resulting in a behaviour more similar to moist wood, but without the unwanted effects of softener migrating out of the material during testing.

The present research focuses on scratch tests of small-scale samples of PEGimpregnated wood. In a scratch test, an indenter is loaded against the surface, and the sample under the tip is moved with a constant velocity. The load applied can be constant or it can be increased with a selected loading speed. Scratch tests were previously used mainly for determining the coating adhesion (Burnett and Rickerby 1987; Ronkainen et al. 1990; Meneve et al. 2001). More precise studies related to crack generation and fracture toughness determination of coatings have also been carried out based on scratch testing (e.g. Holmberg et al. 2003). In addition to metal and ceramic coatings, scratch tests have also been performed on the composites to explore the scratch performance in relation to the fibre orientations of composites (e.g., Beamont et al. 1997). Nanoscratch tests have been adopted to study phenomena related to abrasive scratching induced wear and friction performance of polymer fibres (Cayer-Barrioz et al. 2006). Scratch tests have also been employed to investigate scratching wear and damage in polymer nanocomposites (Dasari et al. 2009). For the scratch testing of materials, such as polymer nanocomposites, the importance of the scale effects has been stated in order to identify the nano-scale effects in nanoscratch testing, since the scratch track dimensions ought to be smaller than or similar in size scale to the characteristic phenomena detected (Dasari et al. 2007). Particularly for polymers, the scratch morphology at low penetration depth is characterized by plastic flow, whereas high penetration was shown to lead to brittle failure (Surampadi et al. 2007). The scratch resistance of furniture lacquer coatings to linear scratching was studied in Banecki (2011). That study demonstrated the reproducibility of the scratch test results in terms of scratch resistance measures, as well as the repeatability of the scratch test results in relation to the tested furniture.

The scratch test results under normal loads are typically given as penetration depth (elastic deformation), residual depth (plastic deformation), frictional forces and frictional coefficients. In addition to the information about scratching friction, the findings on wood plasticity are also useful. Wood has indeed a cellular microstructure with about half of the wood volume consisting of closed voids. The stress-strain curve of cellular solids typically shows a linear elastic part followed by a plateau after the yield point, which originates just from geometry and elastic deformation (Gibson and Ashby 1997; De Magistris and Salmén 2006, 2008). The mechanical behaviour during scratching may change drastically in the presence of plasticity as shown, for example, in Li et al. (2002), where the scratch resistance of gelatine films improved almost by a factor of 10 , when a moderate nanoparticle addition changed the scratching mechanisms from tearing to ductile ploughing.

In indentation tests, a small and geometrically well-defined hard tip is pushed gently into the specimen surface. From the load-displacement data of the indentation experiment, the material hardness and indentation modulus can be determined. In relation 
to the effects of water, the indentation modulus of resin-treated wood provided better correlation with dimensional stability than hardness, as reported in Klüppel (2017), which is because the indentation technique is sensitive to the wood cell modification. Furthermore, the recovery behaviour of wood is influenced by the treatment, as shown in Dumail and Salmén (1997), where the behaviour of water-saturated and ethylene glycol-saturated wood was investigated. By extending the above concepts, the scratch tests on PEG-impregnated wood may provide more information on the dimensional stability of wood under combined compressive and sliding actions compared to the techniques of hardness and indentation testing. Indentation test is also restricted to a small area of the surface, so the information gained represents the properties of a small local area. By using scratch testing, it is possible to collect information from a larger area of the surface, which makes it more informative and versatile. To the knowledge of the authors, the scratch tests of uncoated wood have not been explored in the scientific literature. Therefore, the work presented in this paper is basic research, demonstrating that the scratch testing of PEG-impregnated green wood is a simple technique for evaluating the properties of wood under various swelling conditions and scratch loads in different directions of wood.

The aim of this research is to obtain results that can show the water content stabilization in the tested PEG-impregnated spruce samples at various PEG concentrations, as well as the effects of scratch directions, loads and indenter tip size and material on the scratch resistance, also in relation to the growth ring structure (earlywood and latewood) and the location of specimens with respect to the wood pith. The obtained data for resistance of PEG-impregnated green wood can be used as references for future studies on scratch resistance of untreated or treated dry wood and various wood-based products.

In addition, a preliminary work providing confocal laser scanning microscope pictures of raw, polished and scratched samples allows to visualize the deformation mechanisms of PEG-impregnated green wood cells under the scratches. In the results and discussion section, it is argued that future work by accurate image analysis, along with the scratch testing, could exploit possible similarities between scratch-type loads and loads used in various wood processing involving also water effect such as, for example, the mechanical pulping (De Magistris and Salmén 2006, 2008). Since the typical average diameter of grits in wood grinding (Liimatainen et al. 1999) matches with the typical scratch tip diameter of the scratch tests, this similarity could help in the field of energy saving in mechanical pulping.

\section{Materials and methods}

\section{Preparation of samples and PEG impregnation}

All together 36 small-scale samples of green Norway spruce (Fig. 1), with nominal dimensions of $12 \mathrm{~mm} \times 12 \mathrm{~mm} \times 12 \mathrm{~mm}$ in the radial $(R)$, tangential $(T)$ and longitudinal $(L)$ direction of wood, were cut from one thinning wood block by a circular saw. 
Fig. 1 Green samples of Norway spruce cut for the tests

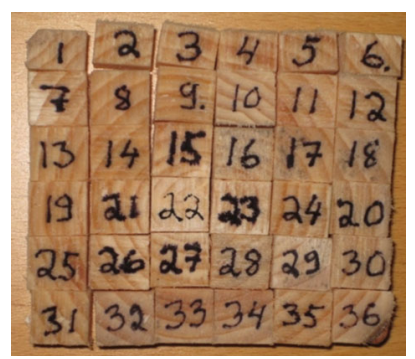

Samples 1, 5, 6 and 36 in Fig. 1 were excluded from the experiments due to poor geometry or incomplete impregnation. Polyethylene glycol (PEG) impregnation of the samples was carried out at Uppsala University at five different impregnation levels. A PEG with low average molecular weight (400) was used. The procedure of impregnation was as follows. Deionised water (dw) was used for mixing of PEG solutions, and the concentration of PEG in the solution was calculated as

$$
\% \text { PEG }=100 \times \frac{\text { weight, } \text { PEG }}{\text { (weight }, \mathrm{dw}+\text { weight }, \text { PEG) }}
$$

The obtained concentrations of PEG in the PEG-water impregnation solution were $0 \%, 25 \%, 50 \%, 75 \%$ and $100 \%$.

Samples were submerged in the solution and kept in a refrigerator at $4{ }^{\circ} \mathrm{C}$ for 2 months. The reason for keeping the samples at this low temperature, which is to some extent slowing down the impregnation process, was to prevent bacterial/fungal growth. No blurring (indicating possible growth of microorganisms) was found in the solutions.

Next, the samples were removed from their baths (water and PEG/water for the references and PEG-impregnated samples, respectively). The samples were blotted gently with a paper towel. Thereafter, the dimensions and weight were registered, and the density of the samples was calculated. The PEG-impregnated samples were left to dry at ambient room temperature in the laboratory (relative humidity RH approximately $43 \%$, temperature $22{ }^{\circ} \mathrm{C}$ ). Furthermore, the dimensions and weight of the non-impregnated samples were registered, and the density of each sample was calculated. This procedure was repeated until the change in weight was negligible. Thereafter, all samples were conditioned for approximately 1 month in a desiccator with a controlled climate (RH 51-53\%, temperature $22-23{ }^{\circ} \mathrm{C}$ ), and dimensions and weights of the samples were measured again.

The volumetric shrinkage $b_{\mathrm{V}}$ was calculated for all the samples as

$$
b_{\mathrm{V}}=b_{\mathrm{R}}+b_{\mathrm{T}}+b_{\mathrm{L}}[\%]
$$

where $b_{\mathrm{R}}, b_{\mathrm{T}}$ and $b_{\mathrm{L}}$ indicate the shrinkage in the radial, tangential and longitudinal direction of wood, respectively. It has to be noted that $b_{\mathrm{V}}$ does not represent the total volumetric shrinkage but the shrinkage between the fully swollen state and the condition at equilibrium moisture content at ambient room conditions, which is estimated 
Table 1 Average density ( $\left.\rho_{\mathrm{AVRG}}\right)$ in water-soaked stage, PEG concentration, average densities after PEG impregnation, drying in air and conditioning in desiccator, and average volumetric shrinkage $\left(b_{\mathrm{V}, \mathrm{AVRG}}\right)$ of wood samples

\begin{tabular}{|c|c|c|c|c|c|c|}
\hline Samples & $\begin{array}{l}\rho_{\text {AVRG }} \\
\text { (water- } \\
\text { soaked) } \\
\left(\mathrm{kg} / \mathrm{m}^{3}\right)\end{array}$ & $\begin{array}{l}\text { PEG con- } \\
\text { centration } \\
(\%)\end{array}$ & $\begin{array}{l}\rho_{\text {AVRG }} \\
\text { (after PEG } \\
\text { treatment) } \\
\left(\mathrm{kg} / \mathrm{m}^{3}\right)\end{array}$ & $\begin{array}{l}\rho_{\text {AVRG }} \\
\text { (after } \\
\text { drying in } \\
\text { air) } \\
\left(\mathrm{kg} / \mathrm{m}^{3}\right)\end{array}$ & $\begin{array}{l}\rho_{\text {AVRG }} \\
\text { (after con- } \\
\text { ditioning in } \\
\text { desiccator) } \\
\left(\mathrm{kg} / \mathrm{m}^{3}\right)\end{array}$ & $\begin{array}{l}b_{\mathrm{V}, \mathrm{AVRG}} \\
(\%)\end{array}$ \\
\hline $\begin{array}{c}3,9,11,18 \\
24,26\end{array}$ & 1074 & 0 & 1122 & No data & 429 & 9.6 \\
\hline $\begin{array}{l}4,12,13, \\
21,27,30\end{array}$ & 25 & 1181 & 870 & 841 & 0.2 & \\
\hline $\begin{array}{c}7,14,16 \\
22,28 \\
32,33\end{array}$ & 1045 & 50 & 1157 & 1027 & 981 & 0.1 \\
\hline $\begin{array}{c}8,15,19 \\
23,29 \\
34,35\end{array}$ & 999 & 75 & 1110 & 1048 & 993 & -0.1 \\
\hline $\begin{array}{l}2,10,17 \\
20,15,31\end{array}$ & 1072 & 100 & 1184 & 1121 & 1067 & -0.1 \\
\hline
\end{tabular}

to be ca 9.5\% following Keylwerth (1964). In addition to volumetric shrinkage, radial shrinkage was also calculated for the sake of comparison. The radial shrinkage is calculated as

$$
b_{\mathrm{R}}=100 \times \frac{l_{\mathrm{R} 1}-l_{\mathrm{R} 2}}{l_{\mathrm{R} 1}}[\%]
$$

where $l_{\mathrm{R} 1}$ and $l_{\mathrm{R} 2}$ are the radial dimensions before and after drying. From the calculations in Table 1, it can be seen that for the lowest impregnation rate (25\% PEG in solution) the volumetric shrinkage also is very small. This means that all the PEG-impregnated samples (regardless of the impregnation rate) were prevented from shrinking. Theoretically, scratch tests could then be performed on samples from an arbitrarily selected group of samples impregnated with PEG, and this would then correspond to scratch testing of fully water-saturated samples. However, one might have to perform tests on samples from different groups anyway, as the PEG penetration in the samples might be, for example, more unevenly distributed for samples at lower impregnation rate as this slows down the penetration rate. A short summary of the measurements described above is shown in Table 1. It has to be noted that the coefficients of variation did not exceed the $9 \%$ in neither case.

\section{Scratch tests}

The scratch tests were carried out at VTT Technical Research Centre of Finland Ltd. To prepare a smooth surface for scratching, a polishing technique was used by cutting a thin slice of the specimen with a microtome (model Leica Jung RM 2055). The CSM 

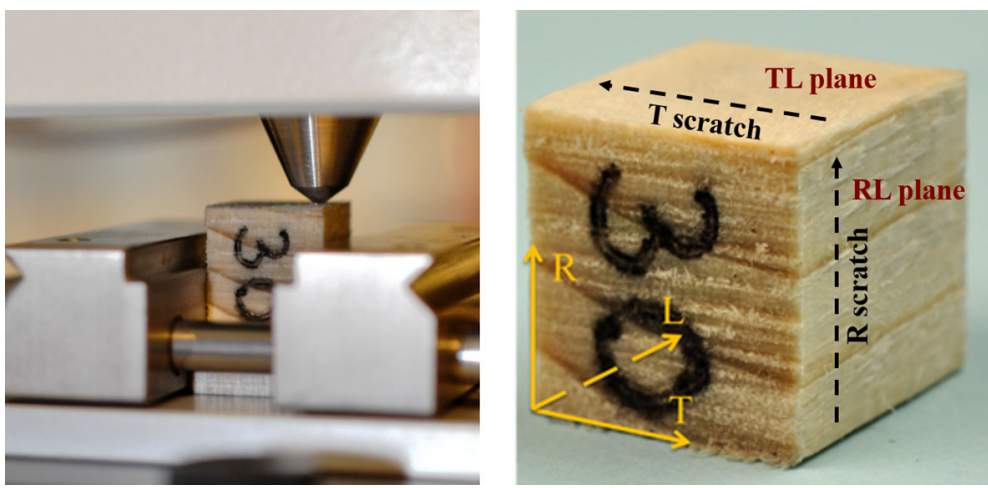

Fig. 2 Left: PEG-impregnated sample of Norway spruce under scratch test indenter. Right: radial $(R)$, tangential $(T)$ and longitudinal $(L)$ directions of wood and examples of scratches close to the edges in the $T$ direction (TL plane) and $R$ direction (RL plane)

Micro-Combi tester was used for scratch testing of one sample from each group of PEG impregnation. Four scratches per sample were made along the two main directions, i.e. the tangential $(T)$ in the tangential-longitudinal (TL) plane, and the radial $(R)$ in the radial-longitudinal (RL) plane of the wood sample (Fig. 2, right). Both the start and the end of each scratch were approximately $1 \mathrm{~mm}$ inside the wood block. The distance of the first scratch from the closest parallel edge of the sample was $2 \mathrm{~mm}$.

A Rockwell $\mathrm{C}$ diamond tip with a radius of $200 \mu \mathrm{m}$ and a steel ball with a radius of $1000 \mu \mathrm{m}$ were used for scratch testing, and two loading modes, constant and continuously increasing load, were adopted. The constant scratch load of $2 \mathrm{~N}$ and increasing load from 0 to $2 \mathrm{~N}$ were used for the diamond tip. For the steel ball tip, a constant scratch load of $4 \mathrm{~N}$ and increasing load from 0 to $4 \mathrm{~N}$ were adopted. Scratching velocity of $10 \mathrm{~mm} / \mathrm{min}$ and the total scratch length of $10 \mathrm{~mm}$ were used with the two tip geometries. Between the scratches, there was a space of $1.5 \mathrm{~mm}$ when using the diamond tip and $2 \mathrm{~mm}$ when using the steel ball. Pre-scan of the scratch path was done prior to scratching using $0.1 \mathrm{~N}$ force to obtain the surface profile as a baseline for penetration depth and residual depth measurements.

During scratching, frictional force was measured and the related friction coefficient was determined as well as the penetration depth of the tip, which describes the combined elastic and plastic deformation. After scratching, another scan was made using $0.1 \mathrm{~N}$ normal force to measure the residual depth of the scratch channel.

\section{Preliminary work on confocal microscopy images of PEG-impregnated swollen samples}

Details on the mechanism of wood cell deformation under scratch were obtained by using the confocal laser scanning microscopy. A microscope ZEISS LSM 710 with Axio Imager 7.2 and objectives EC-Plan Neofluar 10 or 20 x/0.30 M27 were used. The laser had a Diode 405-30 with excitation wavelength $405 \mathrm{~nm}$ and emission wavelengths 

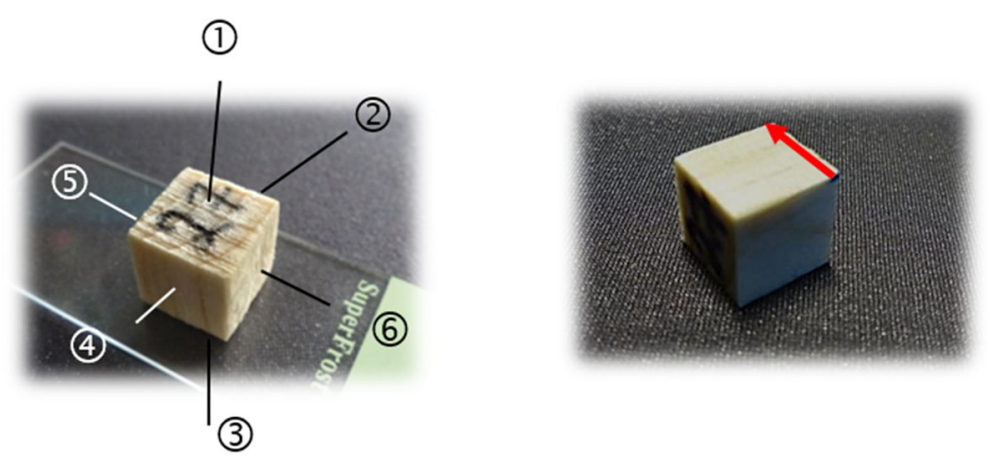

Fig. 3 Left: Sample 27 with sides marked: cross section $(1,3)$, radial $(2,4)$, tangential $(5,6)$. Right: scratching side and direction (arrow, side 2); side 3 is to observe the changes on wood cells due to scratching

$410-514 \mathrm{~nm}$. The frame scan size was $2368 \times 1776$ pixels and the image size $843.9 \times$ $632.9 \mu \mathrm{m}$.

Sample 27 shown in Fig. 3, which has 25\% PEG concentration, was analysed as a representative case study to visualize the cells of swollen wood under the scratch by the larger tip (steel ball with radius $1 \mathrm{~mm}$ ) before and after scratching. The scratch imaged with confocal laser microscopy (Sample 27) was made very close to the edge of the sample in order to capture as much as possible the effects of scratching on the structural features of the sample face beneath the scratched surface.

Scratches in the TL plane of Sample 20, with a PEG impregnation of $100 \%$, were also visualized and commented in relation to the scratch traces in the earlywood and latewood locations.

\section{Results and discussion}

\section{Scratch test results}

The typical results of a scratch test are shown in Fig. 4 with reference to Sample 27 (25\% PEG concentration). The graph shows the normal force, penetration depth, residual depth, frictional force and friction coefficient as a function of the scratch length. These results are obtained for the case of a constant normal force of $4 \mathrm{~N}$ with a steel ball tip with radius of $1 \mathrm{~mm}$.

The scratch resistance is described in this work as a frictional force resisting the scratching movement, and the corresponding penetration depths and residual depths caused by scratching.

Scratches in the $R$ and $T$ directions (in the RL and TL planes of Fig. 2) allow characterization of the variation of mechanical properties, such as scratch resistance and friction coefficient (i.e. frictional force divided by the normal force) caused by the wood material structure, i.e. the annual rings of earlywood and latewood. Because of the variation in the wood material structure, the residual depth and related frictional force vary along the scratch path. Since latewood is harder due to densely layered, 


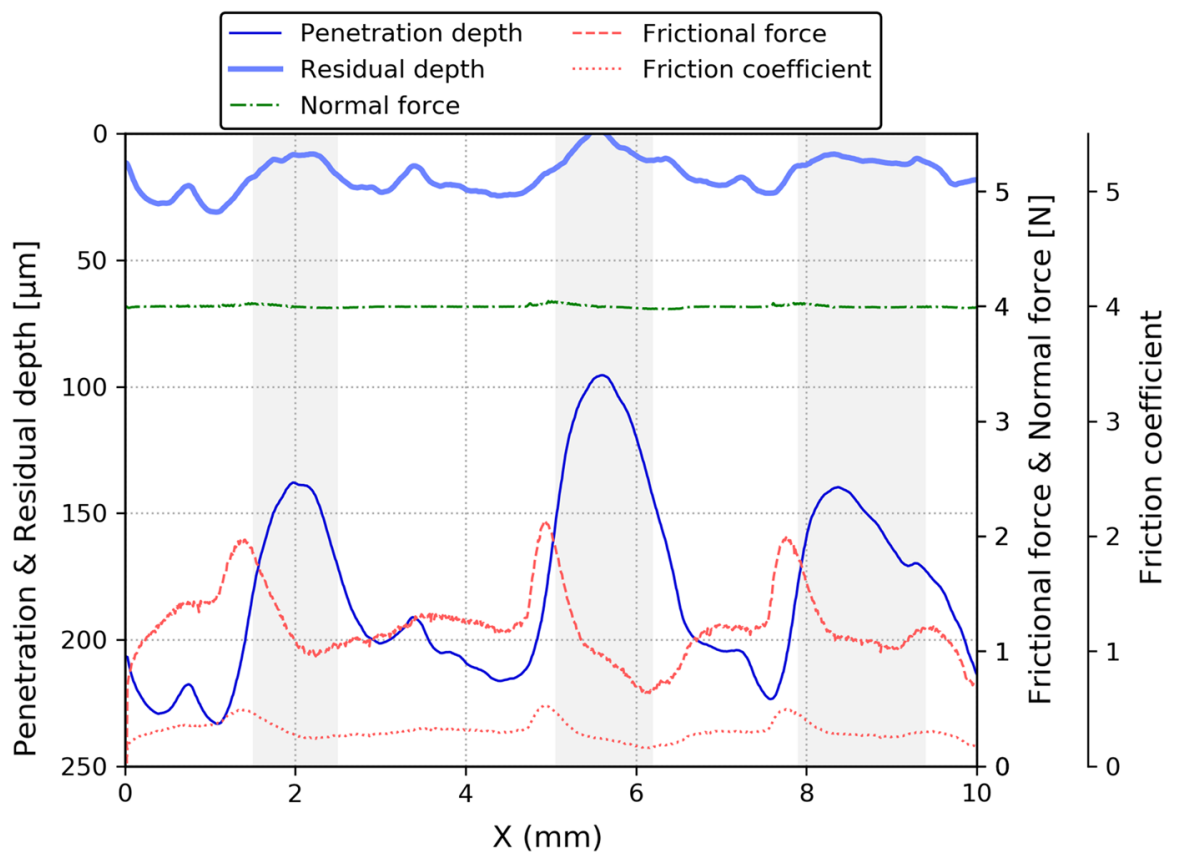

Fig. 4 Results of the scratch test made on Sample 27 (shown in Fig. 3) in the radial direction. The graph shows the normal force $[\mathrm{N}]$, residual depth $[\mu \mathrm{m}]$, penetration depth $[\mu \mathrm{m}]$, frictional force $[\mathrm{N}]$ and friction coefficient $[-]$ as a function of the scratch length $(=10 \mathrm{~mm})$. Approximated locations of latewood shaded

strong, thick-walled cells, the frictional force and the penetration depth are increased when scratching over the latewood areas, as shown in Fig. 4 (shaded areas). The latewood areas are also detected in the residual depth graph.

The results plotted in Figs. 5, 6, 7 and 8 refer to Samples 22 and 32 as representative samples of heartwood close to the wood pith (indicated as centre) and far from the pith (indicated as edge), respectively. Both samples are impregnated with 50\% PEG. In Fig. 5, the penetration depth as a function of the normal force is drawn for the centre and edge samples in both cases of radial and tangential directions also including the error bars. This figure shows the good repeatability of the four scratches made on each tested sample along the chosen direction (tangential in plane TL and radial in plane $\mathrm{RL}$ ). The distance during scratch is also reported on the abscissa.

Figure 6 shows the penetration depths and the corresponding unrecoverable residual depths for the same cases. The penetration depth represents both elastic and plastic deformations of the wood under increasing normal load, and the residual depth represents the remaining plastic deformation of the wood. The graphs clearly show that most of the penetration occurring during scratch testing was recovered on both the centre and edge samples. The large difference (up to about $150 \mu \mathrm{m}$ ) between penetration and residual depth means a significant elastic recovery. In addition, the difference between early- and latewood seems to diminish in residual depth measurements. 


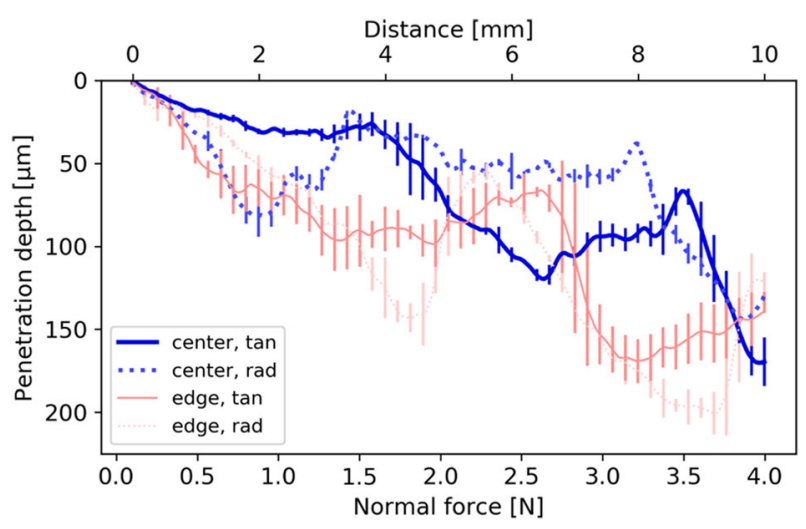

Fig. 5 Penetration depth versus normal force and scratch length for Samples 22 (centre) and 32 (edge) with $50 \%$ PEG. Scratches in radial direction (rad, RL plane) and tangential direction (tan, TL plane). Steel ball (tip radius $1 \mathrm{~mm}$ ) was used with increasing normal force from 0 to $4 \mathrm{~N}$. Error bars included

In Fig. 7, a summary of all involved quantities (penetration, residual depth, frictional force and normal forces as a function of the scratch length) is shown for Sample 32 (centre), including the approximated locations of latewood (shaded).

In Fig. 8, the scratch resistance described as the frictional force during scratch testing is shown for both tangential and radial direction of wood for Samples 22 and 32 with increasing normal force $0-4 \mathrm{~N}$. The samples far from the pith are found to exhibit a higher scratch resistance with higher values in the tangential direction. This can be explained by the vicinity of the edge samples to the sapwood zone, which is characterized by a higher density. The scratch resistance peaks in Fig. 8 correspond to the peaks of penetration depth and residual depth of Figs. 5, 6 and 7 that appear in the presence of latewood zones due to the higher local density. Latewood locations can be observed as the depth decreases when encountering harder wood. The latewood locations are preceded by higher frictional forces as the softer earlywood is pushed against the latewood "wall". Latewood locations are followed by an increase in penetration depths and lower frictional forces in earlywood locations.

The effect of different PEG impregnations on the penetration depth, residual depth and frictional force is quantified in Figs. 9, 10, 11 and 12. Figure 9 shows the mean penetration depths and mean residual depths for all tests (including the constant forces and the two different tip sizes) as a function of the PEG concentrations. The results in Fig. 9 reveal that residual depths from 25 to $100 \%$ PEG concentration are quite similar but smaller compared to the one for $0 \%$ PEG. On the contrary, the penetration depths from 25 to $100 \%$ PEG concentration are also similar but larger than the one for $0 \%$ PEG, meaning that the non-impregnated wood samples ( $0 \%$ PEG) do not recover from scratching as good as the ones with PEG impregnation.

Figure 10 presents the mean frictional forces as a function of the PEG concentration for the two tip sizes and the constant forces used. The linear trendlines and their equations are also presented. The frictional force is linked to the penetration depth as larger penetration creates higher friction, and with the geometries used here, also a wider "wall" to plough through. The smallest frictional force is observed at $0 \%$ PEG 

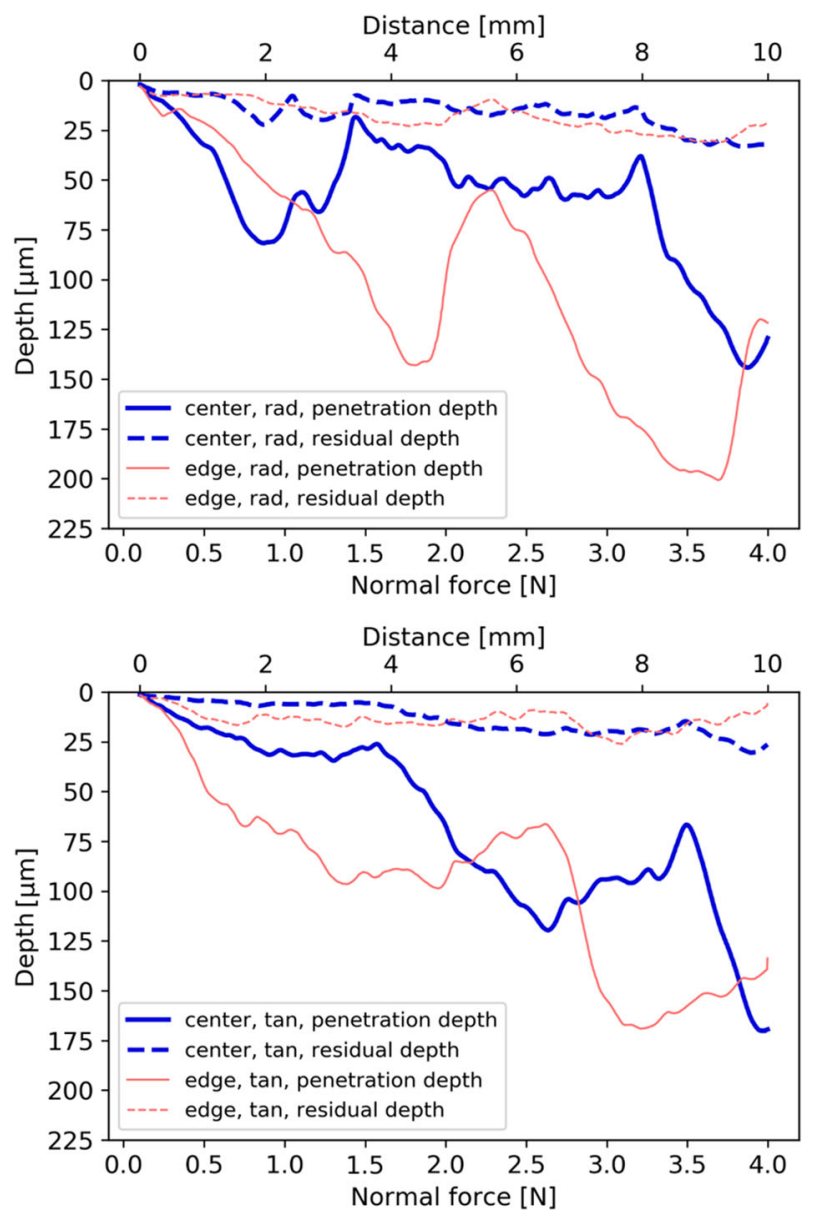

Fig. 6 Penetration and residual depth vs normal force and scratch length for Samples 22 (centre) and 32 (edge) with 50\% PEG. Scratches in radial direction (rad, in RL plane), top and tangential direction (tan, in TL plane), bottom. Steel ball (tip radius $r=1 \mathrm{~mm}$ ) with increasing normal force from 0 to $4 \mathrm{~N}$ was used for scratching

for both tips. In the part of Fig. 10 related to the smaller tip, the penetration depths were quite constant with or without PEG, but the frictional force is higher with PEG than without it, which shows that the consistency of the "wall" also matters. For the larger tip, the frictional force increases with increasing PEG impregnation rate, as did the penetration depth. The mean friction coefficients for all samples, also including the ones with progressive normal force, are reported in Fig. 11 as a function of the PEG concentration and in Fig. 12 as a function of the density. The linear trendlines and their equations are also shown in these Figures. Friction coefficient values are lower with the larger tip compared to the smaller tip size. Figure 11 shows that the friction coefficient increases with increasing PEG amount, especially with the larger tip due to the increase in penetration depth, and thus the frictional force. Figure 12 

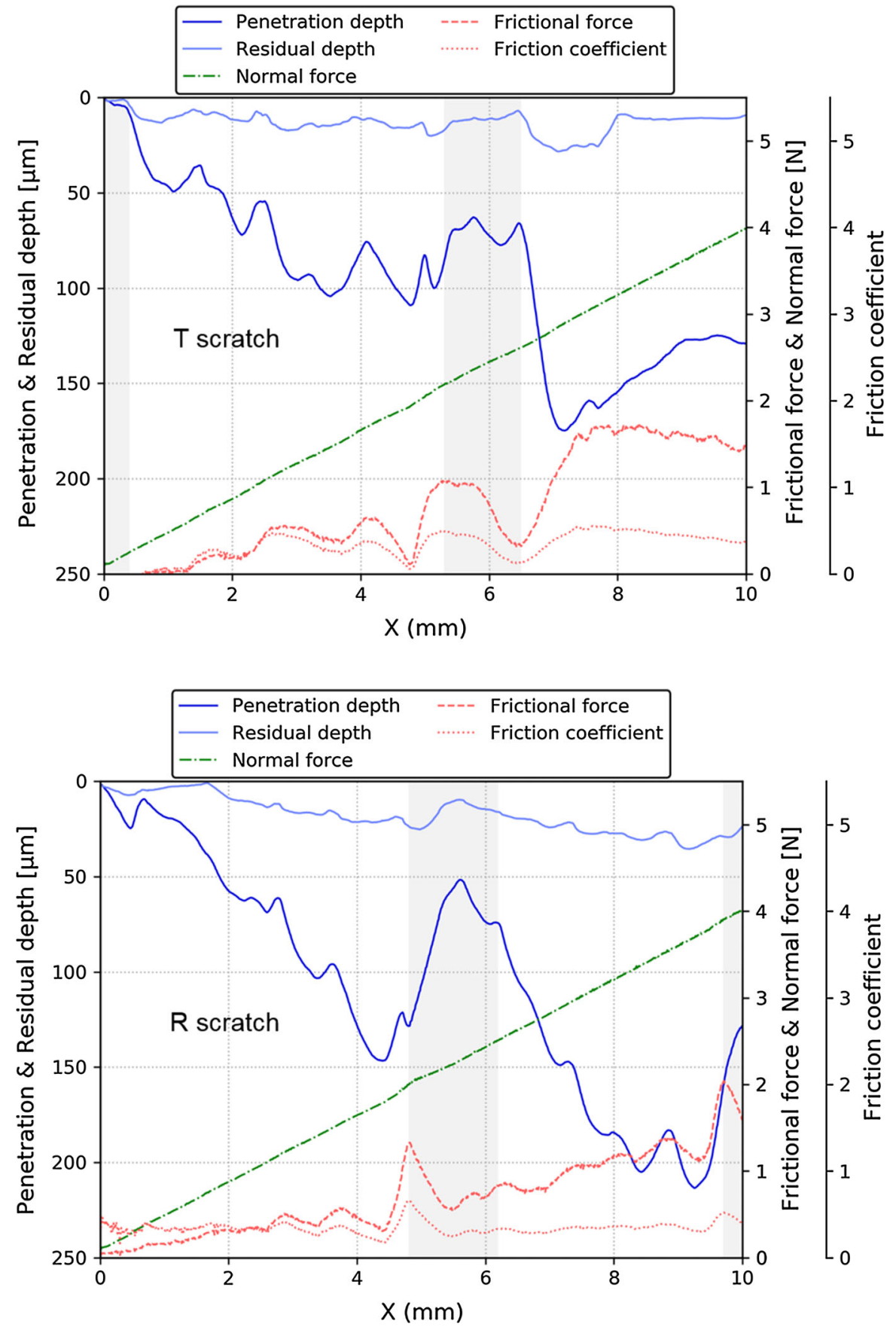

Fig. 7 Penetration, residual depth, frictional force and normal forces as a function of the scratch length for Sample 32 (edge) with 50\% PEG. Scratches in radial direction ( $R$ scratch, RL plane), top and tangential direction ( $T$ scratch, TL plane), bottom. Steel ball (tip radius $r=1 \mathrm{~mm}$ ) with increasing normal force from 0 to $4 \mathrm{~N}$ was used for scratching. Approximated locations of latewood shaded 


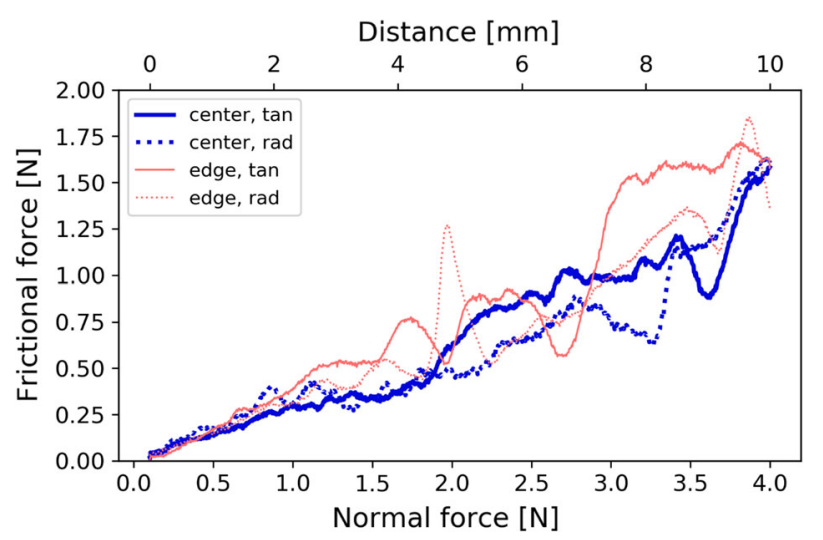

Fig. 8 Frictional force versus normal force and scratch length (distance) for samples 22 (centre) and 32 (edge) with 50\% PEG in radial (rad, in RL plane) and tangential direction (tan, in TL plane). Steel ball (tip radius $r=1 \mathrm{~mm}$ ) was used with increasing normal force from 0 to $4 \mathrm{~N}$

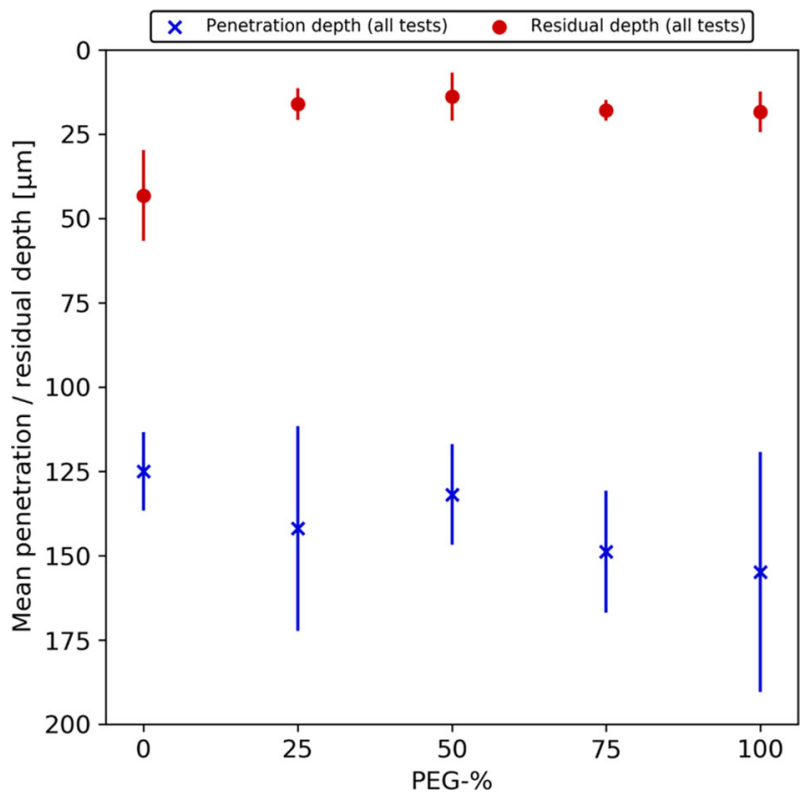

Fig. 9 Mean penetration depth (bars with crosses) and mean residual depth (bars with circles in scratch tests carried out in all tests, including the results for steel ball (tip radius $r=1 \mathrm{~mm}$ ) with constant load of $4 \mathrm{~N}$, and diamond tip (radius $r=0.2 \mathrm{~mm}$ ) with constant load of $2 \mathrm{~N}$. All sample groups at different PEG concentrations

shows that the friction coefficient also depends on the density, with higher density providing higher friction coefficient. The lowest friction was measured for samples with low density, which represent the samples with 0\% PEG. In addition, in this case, the large tips provided lower friction compared to small tips. The 0\% PEG samples, which also had the lowest density, differed in performance from the PEG-impregnated 


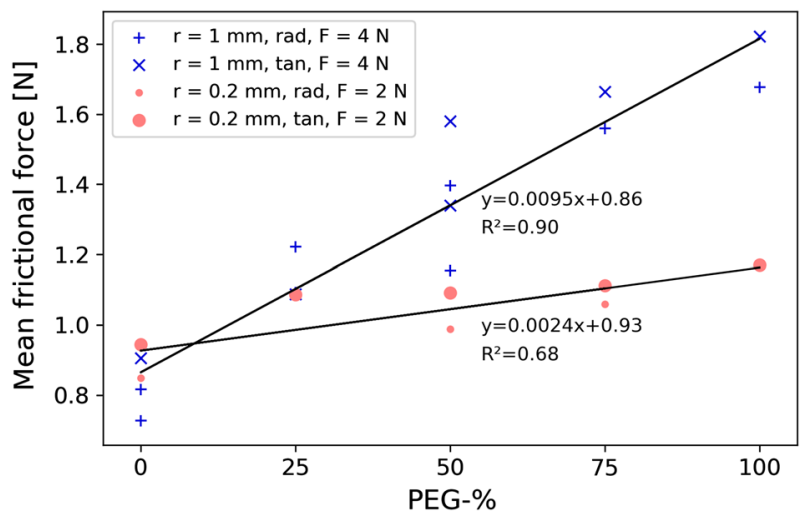

Fig. 10 Mean frictional force in radial (rad) and tangential (tan) direction at constant normal forces for all tests. Steel ball tip (radius $r=1 \mathrm{~mm}$ ) with constant load of $4 \mathrm{~N}$, and diamond tip (radius $r=0.2 \mathrm{~mm}$ ) with constant load of $2 \mathrm{~N}$ were applied. All sample groups at different PEG concentrations

samples. Therefore, the results shown in Figs. 11 and 12 confirm the effect of water stabilization due to PEG impregnation.

The differences in scratch resistance between radial and tangential directions are negligible based on the depth and frictional force results shown in Figs. 9 and 10 which is in agreement with the similarity of wood properties in the radial-tangential plane. On the contrary, the impact of scratch tip size is relevant for the frictional force (Fig. 10), and this behaviour is related to wood plasticity. It can be observed that the indenter tip size has an effect on the penetration depths and, consequently, on the whole scratch resistance performance.

A summary of the results is reported in Table 2 (steel ball tip) and Table 3 (diamond tip) for the tested normal loads. The tables show that larger friction, increasing as a function of PEG concentration and density, especially at high PEG, is related to the smaller tip and to larger plastic behaviour.

\section{Preliminary results on confocal microscopy images of PEG-impregnated swollen samples}

Confocal laser microscopy images in Fig. 13 show the wood cells before and after a polishing technique needed to gain a clean scratch surface, as already pointed out in "Scratch tests" section. The dimensions of nearly hexagonal cells were measured using the ImageJ code (Schneider et al. 2012) after the polishing and are reported in Table 4 for the earlywood, transition wood and latewood structures. The visible cell deformation before scratching is due to the cuts done to prepare the cubic samples. 

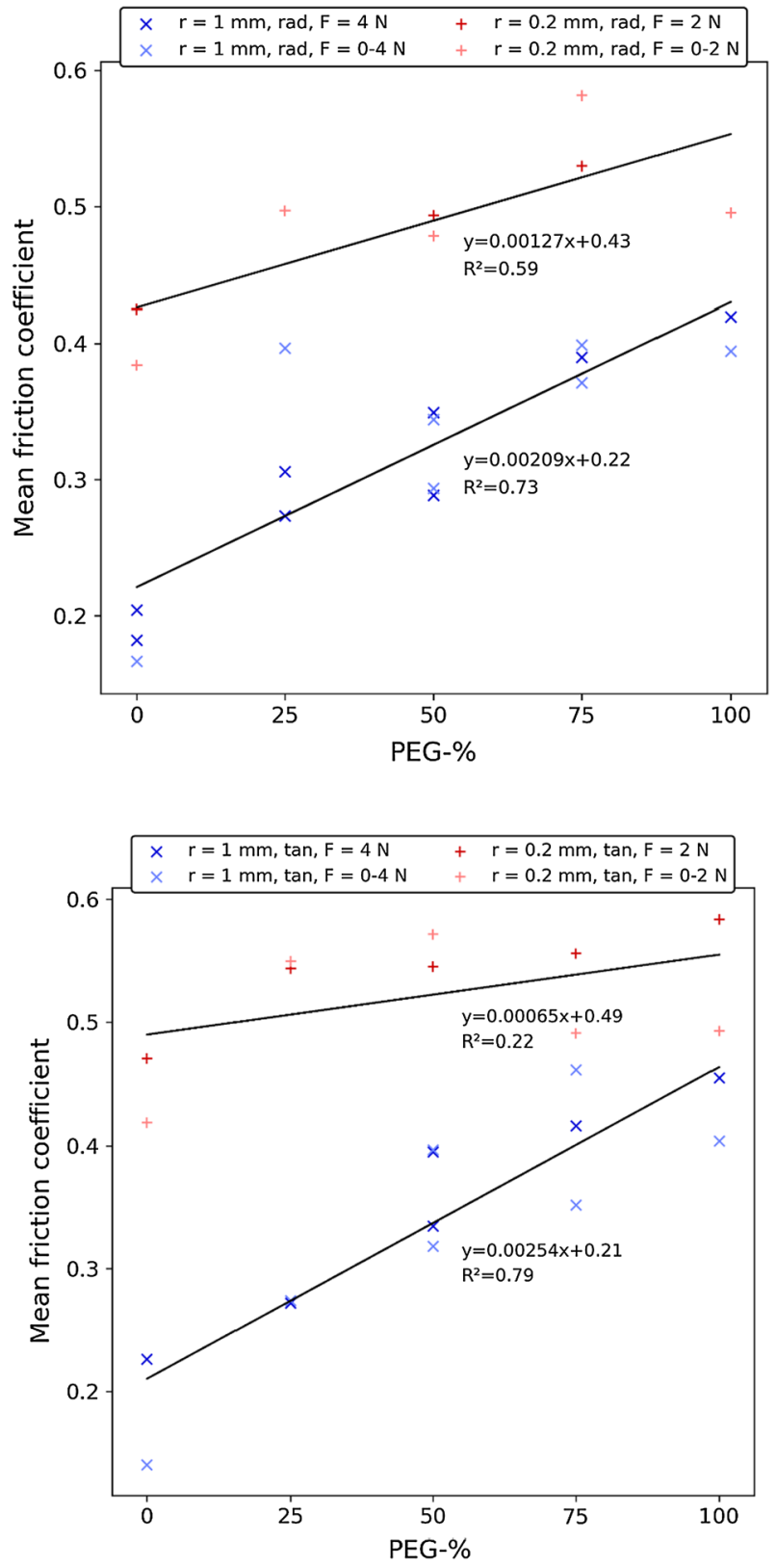

Fig. 11 Mean friction coefficient (over all samples) as a function of PEG concentration in radial (rad, RL plane) and tangential (tan, TL plane) scratch directions for all tests. Steel ball (radius $r=1 \mathrm{~mm}$ ) with constant normal load of $4 \mathrm{~N}$ or increasing load from 0 to $4 \mathrm{~N}$, and diamond tip (radius $r=0.2 \mathrm{~mm}$ ) with constant normal load of $2 \mathrm{~N}$ or increasing load from 0 to $2 \mathrm{~N}$ were applied in tests

Figure 14 shows the deformed as well as the collapsed wood cells on the polished surface of Sample 27 after the scratch testing. The scratch was done with the larger tip 

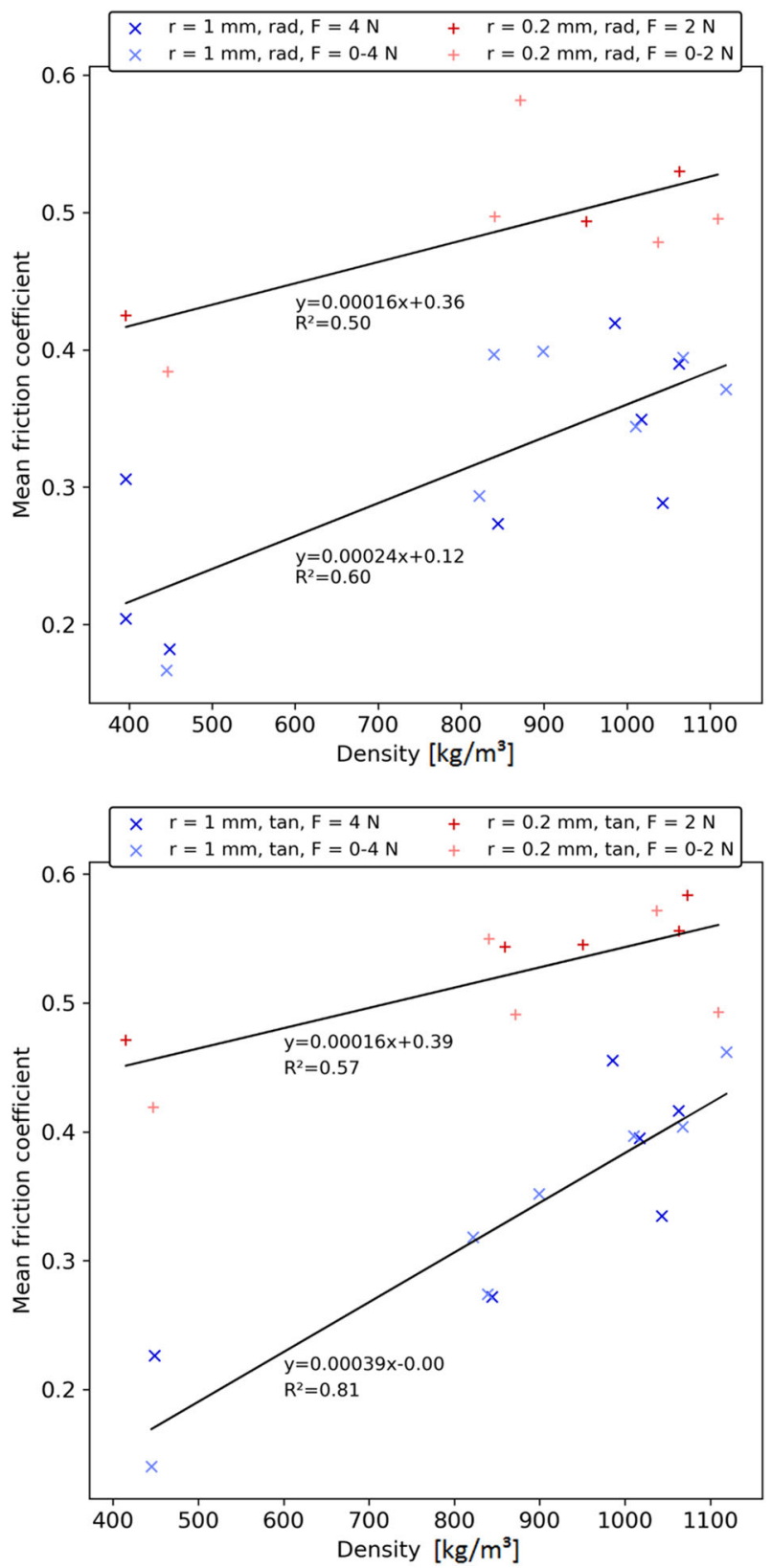

Fig. 12 Mean friction coefficient (over all samples) as a function of density in radial (rad, RL plane) and tangential (tan, TL plane) scratch directions for all tests. Steel ball (radius $r=1 \mathrm{~mm}$ ) with constant normal load of $4 \mathrm{~N}$ or increasing load from 0 to $4 \mathrm{~N}$, and diamond tip (radius $r=0.2 \mathrm{~mm}$ ) with constant normal load of $2 \mathrm{~N}$ or increasing load from 0 to $2 \mathrm{~N}$ were applied in the tests 
Table 2 Summary of scratch results, steel ball tip (radius $r=1 \mathrm{~mm}$ ), constant normal force of $4 \mathrm{~N}$

\begin{tabular}{|c|c|c|c|c|c|c|c|}
\hline \multirow[t]{2}{*}{ PEG (\%) } & \multirow{2}{*}{$\begin{array}{l}\text { Density }\left(\mathrm{kg} / \mathrm{m}^{3}\right) \\
\text { Mean }\end{array}$} & \multicolumn{2}{|c|}{$\begin{array}{l}\text { Penetration } \\
\text { depth }(\mu \mathrm{m})\end{array}$} & \multicolumn{2}{|c|}{$\begin{array}{l}\text { Residual } \\
\text { depth }(\mu \mathrm{m})\end{array}$} & \multirow[t]{2}{*}{ Recovery (\%) } & \multirow{2}{*}{$\begin{array}{l}\text { Friction coefficient } \\
(-) \\
\text { Mean }\end{array}$} \\
\hline & & Mean & SD & Mean & SD & & \\
\hline 0 & 429 & 119.3 & 1.8 & 36.0 & 5.3 & 70 & 0.20 \\
\hline 25 & 841 & 145.2 & 14.0 & 16.6 & 3.7 & 88 & 0.28 \\
\hline 50 & 981 & 124.9 & 7.8 & 10.2 & 7.4 & 92 & 0.34 \\
\hline 75 & 993 & 161.6 & 6.0 & 16.0 & 4.4 & 90 & 0.40 \\
\hline 100 & 1067 & 174.3 & 14.6 & 20.4 & 4.2 & 88 & 0.43 \\
\hline
\end{tabular}

Table 3 Summary of scratch results, diamond tip (radius $r=0.2 \mathrm{~mm}$ ), constant normal force of $2 \mathrm{~N}$

\begin{tabular}{lllllllll}
\hline PEG $(\%)$ & Density $\left(\mathrm{kg} / \mathrm{m}^{3}\right)$ & $\begin{array}{l}\text { Penetration } \\
\text { depth }(\mu \mathrm{m})\end{array}$ & & $\begin{array}{l}\text { Residual } \\
\text { depth }(\mu \mathrm{m})\end{array}$ & Recovery $(\%)$ & $\begin{array}{l}\text { Friction coefficient } \\
(-)\end{array}$ \\
\cline { 3 - 5 } & Mean & Mean & SD & Mean & SD & Mean \\
\hline 0 & 429 & 133.4 & 3.6 & 54.0 & 4.4 & 60 & 0.45 \\
25 & 841 & 131.9 & 2.7 & 14.1 & 1.5 & 89 & 0.54 \\
50 & 981 & 145.7 & 5.7 & 21.4 & 2.1 & 85 & 0.52 \\
75 & 993 & 136.0 & 8.1 & 20.1 & 3.7 & 85 & 0.54 \\
100 & 1067 & 115.9 & 4.9 & 14.3 & 3.7 & 88 & 0.58 \\
\hline
\end{tabular}
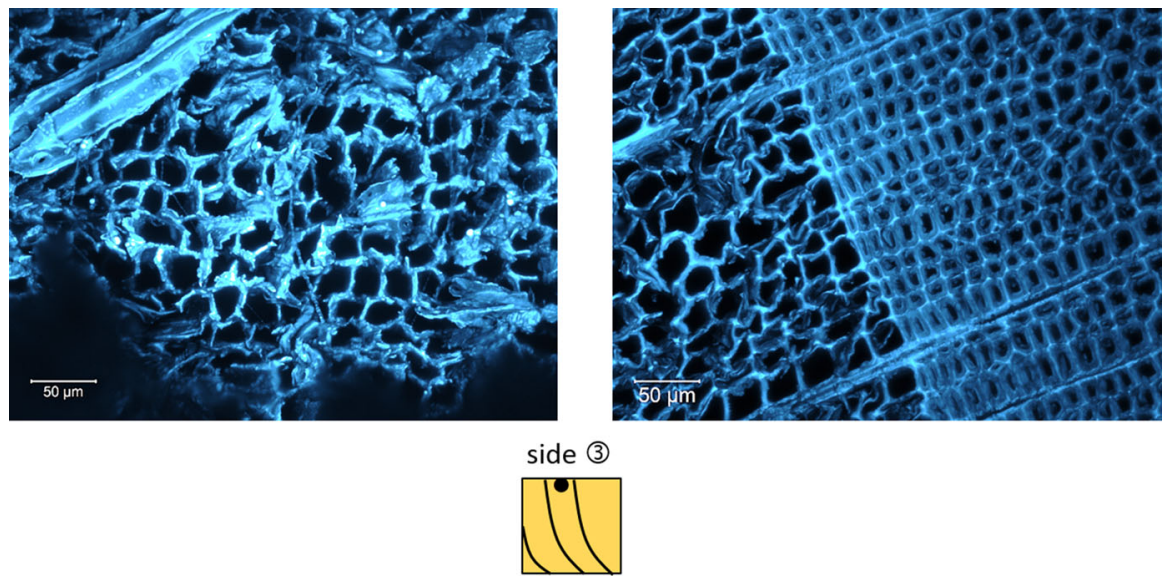

Fig. 13 Confocal laser microscopy pictures of Sample 27 before scratching. Left: raw sample. Right: polished sample. Bottom: location for observation of wood cells (black dot)

(steel ball, radius of $1 \mathrm{~mm}$ ) in the vicinity of the sample edge. The plastic deformation during scratching, identified by residual depth, appears under tip compression at the softest porous region (earlywood) far below the tip penetration depth. 
Table 4 Dimensions of nearly hexagonal wood cells before scratching for earlywood (EW), transition wood (TW) and latewood (LW) microstructures

\begin{tabular}{|c|c|c|c|c|c|c|c|c|c|}
\hline & \multicolumn{3}{|c|}{ Side length $(\mu \mathrm{m})$} & \multicolumn{3}{|c|}{$\begin{array}{l}\text { Cell wall } \\
\text { thickness }(\mu \mathrm{m})\end{array}$} & \multicolumn{3}{|c|}{ Cell wall angle $\left({ }^{\circ}\right)$} \\
\hline & EW & TW & LW & EW & TW & LW & EW & TW & LW \\
\hline Mean & 12.3 & 9.2 & 5.9 & 4.2 & 5.8 & 7.5 & 20.6 & 17.2 & 30.8 \\
\hline SD & 1.8 & 1.7 & 1.2 & 0.9 & 1.1 & 0.9 & 11.8 & 10.3 & 10.7 \\
\hline
\end{tabular}
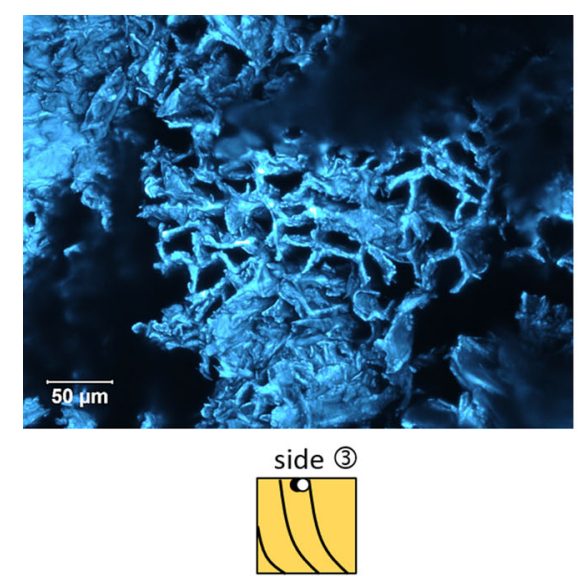
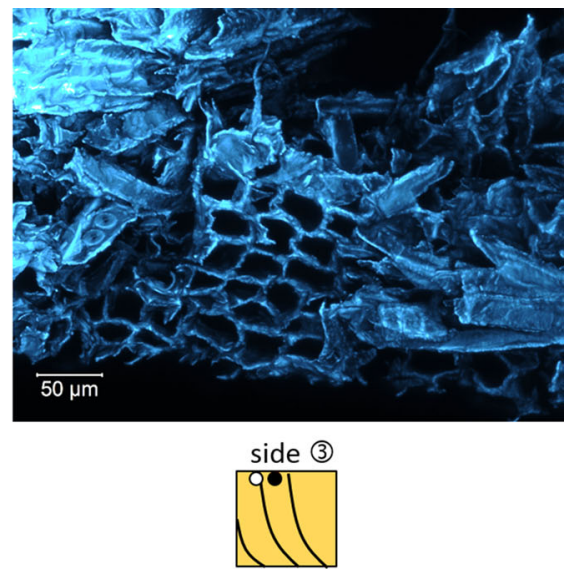

Fig. 14 Confocal laser microscopy pictures from the scratched area (polished surface) on Sample 27 (steel ball with radius of $1 \mathrm{~mm}$ ) showing two different deformed locations. The white dots on the left and right on the schematic picture of the wood represent the deformed areas, and the black dots represent the locations of the cells in the undeformed configuration

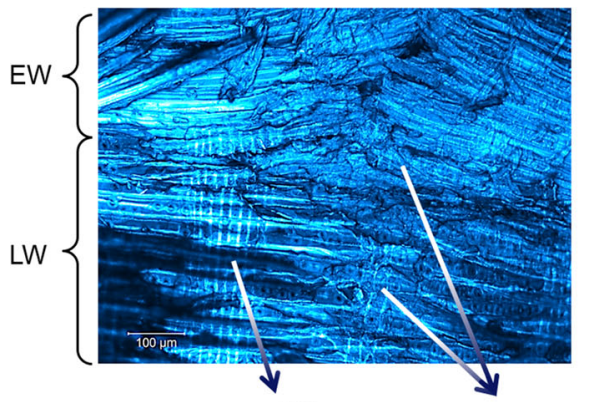

ray-cell line

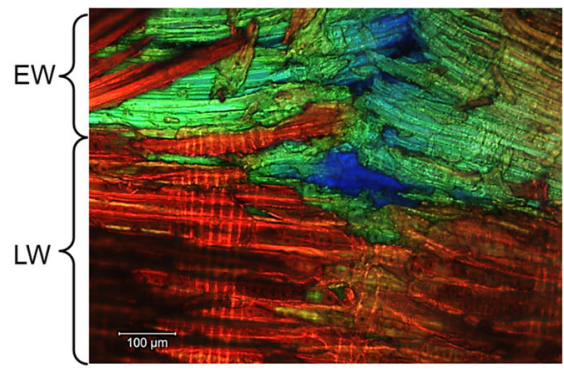

scratching traces

Fig. 15 Confocal laser microscopy pictures on the TL plane of Sample 20 (steel ball with radius of $1 \mathrm{~mm}$ ). Left: normal view. Right: topographic view

Figure 15 shows the normal view and the topographic view under scratch made on plane TL in Sample 20. The figures reveal the thin-walled asset of earlywood that exhibits lower resistance to deformation, and the thick-walled asset of latewood that shows higher resistance.

The wood cell deformation captured by this preliminary work (Fig. 14) appears irregular when compared, for example, to the cell wall deformation under pulp- 
ing type loads shown in De Magistris and Salmén (2006, 2008). More accurate microscopy images (magnification $>25,000-30,000$ ), along with the proposed experimental approach, could be used as an experimental tool in the analysis of grinding grit choice and surface phenomena in mechanical pulping, which is an energy intensive process. The geometry of scratch test resembles weakly the geometry of tools in wood grinding, where the logs are pressed against a grinding stone to produce mechanical pulp fibers for board and paper manufacture. The grinding stone consists of grits, diameter order of $0.2 \mathrm{~mm}$ (Liimatainen et al. 1999). The tip velocity in grinding is faster, typically $20 \mathrm{~m} / \mathrm{s}$, and the wood is wet and warm during the process. The properties of wood depend on water content, temperature and dynamics of the loading. Therefore, it would be interesting to study the differences between the same mechanical properties under scratch tests and during wood grinding. In future research, scratch tests could also be performed in hot water.

More accurate confocal microscopy images could also help to develop numerical models for wood cell deformation (Fortino et al. 2015; Salmén and Burgert 2009).

\section{Conclusion}

In this research, the scratch test on PEG-impregnated green wood samples was introduced as a novel tool for wood research. With the scratch test, it was possible to study the elastic and plastic deformation of wood and to distinguish the influence of structural features of wood, such as early- and latewood, on the performance of wood.

Important basic research findings of the performed scratch tests are as follows:

- The friction coefficient between the tip and PEG-impregnated green wood is nearly independent from the scratch direction in the radial-tangential plane. Wood mechanical properties are known to be quite similar in radial and tangential directions; therefore, this is an expected result.

- There is friction dependence on wood moisture and tip size. The tip size dependence might well result from wood plasticity.

It was demonstrated that scratch testing of PEG-impregnated green wood is suitable to evaluate the properties of swollen wood and scratch test parameters in various directions of wood by providing quantitative values of the frictional forces as well as the total and plastic deformations. Therefore, it was also possible to assess swollen wood reference data with quantitative values of penetration depths under scratches with different percentages of PEG impregnation, which can be useful for future scratch test research on other types of wood and wood-based composites.

The obtained results show that the resistance of wood to scratch loads increases with the reduction in the cutting tip size, as well as with the increase in water stabilization. This information is useful for the understanding of the initiation of mechanisms governing the fracture of wood and wood fibres.

Furthermore, the scratch tests may provide more profound information on the scratch resistance of products prone to scratching, such as wood and wood-based products, instead of only having knowledge of hardness and indentation modulus of the wood. 
In future work, the results of the scratch tests, in combination with confocal laser microscopy or other image-based techniques, could help to develop micromechanicsbased numerical models for wood cell deformation and disintegration. More focused results of scratch tests could also benefit the optimization of process parameters in mechanical pulping and therefore give some suggestions for energy savings, which could be achieved by changing the test parameters such as PEG concentration, scratch tips and loading rates.

Finally, the scratch tests can be used to study the wood fibre-based composites. In scratch tests on these composites, debonding between the wood fibre and the surrounding matrix is a challenging topic, making this technique interesting for future research.

Acknowledgements Open access funding provided by Technical Research Centre of Finland (VTT). The scratch tests and confocal laser scanning microscopy were funded by the VTT MultiDesign Innovation Programme. The analysis of results was supported, in part, by the project DigiMoist1 (A Digital enduser toolset for Moisture assessment in Wooden buildings, 1st part: Hygro-thermal database), funded by the Ministry of the Environment of Finland. The Authors would like to especially thank Prof. Kristofer Gamstedt from University of Uppsala for his valuable comments on this research.

\section{Compliance with ethical standards}

Conflict of interest On behalf of all authors, the corresponding author states that there is no conflict of interest.

Open Access This article is licensed under a Creative Commons Attribution 4.0 International License, which permits use, sharing, adaptation, distribution and reproduction in any medium or format, as long as you give appropriate credit to the original author(s) and the source, provide a link to the Creative Commons licence, and indicate if changes were made. The images or other third party material in this article are included in the article's Creative Commons licence, unless indicated otherwise in a credit line to the material. If material is not included in the article's Creative Commons licence and your intended use is not permitted by statutory regulation or exceeds the permitted use, you will need to obtain permission directly from the copyright holder. To view a copy of this licence, visit http://creativecommons.org/licenses/by/4.0/.

\section{References}

Banecki J (2011) Comparative studies of furniture lacquer coatings' resistance to linear scratching acc. to the method described in TS 15186:2005. Drewno Pr Nauk Donies Komunik 54(185):61-80

Beamont M, Farris TN, Sun CT (1997) Scratch testing of advanced composite surfaces. Compos Part A 28:683-686

Bjurhager I, Ljungdahl J, Wallström L, Gamstedt K, Berglund LA (2010) Towards improved understanding of PEG-impregnated waterlogged archaeological wood: a model study on recent oak. Holzforschung 64:243-250

Burnett PJ, Rickerby DS (1987) The relationship between hardness and scratch adhesion. Thin Solid Films 154:403-416

Cayer-Barrioz J, Mazuyer D, Tonck A, Kapsa P, Chateauminois A (2006) Nanoindentation and friction: an innovative approach to understand the tribological behaviour of polyamide fibres. Tribol Int 39:62-69

Dasari A, Yu Z-Z, Mai Y-W (2007) Nanoscratching of nylon 66-based ternary nanocomposites. Acta Mater 55:635-646

Dasari A, Yu Z-Z, Mai Y-W (2009) Fundamental aspects and recent progress on wear/scratch damage in polymer nanocomposites. Mater Sci Eng R 64:31-80 
De Magistris F, Salmén L (2006) Mechanical behaviour of wet wood in sequences of compression and combined compression and shear. Nord Pulp Pap Res J 21(2):231-236

De Magistris F, Salmén L (2008) Finite element modelling of wood cell deformation transverse to the fibre axis. Nord Pulp Pap Res J 23(2):240-246

Dumail A, Salmén L (1997) Compression behaviour of saturated wood perpendicular to grain under large deformations-comparison between water-saturated and ethylene glycol-saturated wood. Holzforschung 51(4):296-302

Fortino S, Hradil P, Salminen LI, De Magistris F (2015) A 3D micromechanical study of deformation curves and cell wall stresses in wood under transverse loading. J Mater Sci 50(1):482-492

Gibson LJ, Ashby MF (1997) Cellular solids. Structures and properties. Cambridge University Press, Cambridge

Holmberg K, Laukkanen A, Ronkainen H, Wallin K, Varjus S (2003) A model for stresses, crack generation and fracture toughness calculation in scratched TiN-coated steel surfaces. Wear 254:283-291

Keylwerth R (1964) Betriebsblatt 1, Sorptionsgleichgewicht von Holz. Holz Roh-Werkst 22(1):31

Klüppel A (2017) Hardness and indentation modulus of resin-treated wood. Int Wood Prod J 8(1):41-44

Kollmann FFP, Côte WA Jr (1968) Principles of wood science and technology. Springer, Heidelberg

Li T, Chen Q, Schadler LS, Siegel RW, Mendel J, Irvin C Jr (2002) Scratch behaviour of nanoparticle $\mathrm{Al}_{2} \mathrm{O}_{3}$-filled gelatin films. Polym Compos 23(6):1076-1086

Liimatainen H, Haikkala P, Lucander M, Karojärvi R, Tuovinen O (1999) Mechanical pulping. In: Sundholm J, Gullichsen J, Paulapuro H (eds) Grinding and pressure grinding. Book 5 (Papermaking Science and Technology). Fapet Oy, Helsinki, pp 107-156

Meneve J, Ronkainen H, Andersson P, Verkammen K, Camino D, Teer DG, von Stabut J, Gee MG, Jennet NM, Banks J, Bellaton B, Matthaei-Schultz E, Vetters H (2001) Scratch adhesion testing of coated surfaces—challenges and new directions. In: Mittal KL (ed) Adhesion measurement of films and coatings, vol 2. VSP BV, Ridderprint bv, Ridderkerk, The Netherlands, pp 79-106. ISBN 90-6764338-6

Reid SR, Zhou G (eds) (2000) Impact behaviour of fibre-reinforced composite materials and structures. Woodhead Publishing Limited, Sawston

Ronkainen H, Holmberg K, Fancey K, Matthews A, Matthes B, Broszeit E (1990) Comparative tribological and adhesion studies of some titanium-based ceramic coatings. Surf Coat Technol 43(44):888-897

Salmén L, Burgert I (2009) Cell wall features with regard to mechanical performance. A review COST Action E35 2004-2008: wood machining-micromechanics and fracture. Holzforschung 63(2):121-129

Schneider CA, Rasband WS, Eliceiri KW (2012) NIH Image to ImageJ: 25 years of image analysis. Nat Methods 9:671-675

Song S, Chen C, Zhu S, Zhu M, Dai J, Ray U et al (2018) Processing bulk natural wood into a highperformance structural material. Nature 554:224-228

Surampadi NL, Ramisetti NK, Misra RDK (2007) On scratch deformation of glass fiber reinforced nylon 66. Mater Sci Eng A 456:230-235

Publisher's Note Springer Nature remains neutral with regard to jurisdictional claims in published maps and institutional affiliations. 